\title{
Volunteered Geographic Information for Disaster Risk Reduction-The Missing Maps Approach and Its Potential within the Red Cross and Red Crescent Movement
}

\author{
Stefan Scholz ${ }^{1}$, Paul Knight ${ }^{2}$, Melanie Eckle ${ }^{3}$, Sabrina Marx ${ }^{3, *}$ and Alexander Zipf ${ }^{3} \mathbb{C}$ \\ 1 German Red Cross, International Cooperation, 12205 Berlin, Germany; s.scholz@drk.de \\ 2 British Red Cross, GIS, 44 Moorfields, London EC2Y 9AL, UK; paulknight@redcross.org.uk \\ 3 GIScience Research Group, Institute of Geography, Heidelberg University, 69120 Heidelberg, Germany; \\ eckle@uni-heidelberg.de (M.E.); zipf@uni-heidelberg.de (A.Z.) \\ * Correspondence: marx@uni-heidelberg.de; Tel.: +49-6221-54-19703
}

Received: 12 July 2018; Accepted: 1 August 2018; Published: 7 August 2018

\begin{abstract}
For the last few years, the increasing need for humanitarian support has led to increasing demand and responsibilities for the international humanitarian system. This trend raises questions regarding the use of alternative and complementary data sources and potential additional actors and communities that could be involved in support efforts and cover some of the tasks of humanitarian organizations. The article provides an overview of the Red Cross and Red Crescent movement, their practices and activities as well as current needs and challenges. The article illustrates the potential of OpenStreetMap and digital volunteers for humanitarian activities, with a particular focus on disaster risk reduction in the scope of the Missing Maps project. The background and objective of the collaborative project as well as its potential and impact for the Red Cross and Red Crescent movement are elucidated. The conclusion and outlook section presents future plans and visions to make further use of the potential of the Missing Maps approach in additional sectors and contexts.
\end{abstract}

Keywords: OpenStreetMap; Missing Maps; Red Cross and Red Crescent movement; digital volunteers; volunteered geographic information; Vulnerability and Capacity Assessments

\section{Introduction}

The humanitarian needs are increasing all around the world. Currently, more than 134 million people are in need of humanitarian assistance [1,2]. This includes those affected by conflicts and natural disasters. Humanitarian actors, such as United Nations Agencies, Non-Governmental Organizations (NGOs) and the Red Cross and Red Crescent Movement, strive to support those in need. Climate change is exacerbating the effects of natural hazards, such as floods, extreme storms or heat waves. The level of exposure of communities is determined by the vulnerability and capacity of the community to respond and adapt to the risk [3]. To reduce the severe consequences of natural hazards, the humanitarian system focuses on measures to reduce disaster risks. Relevant actions include risk analysis, disaster prevention and mitigation measures as well as measures for strengthening the preparedness of communities in most affected areas. As natural hazards are likely to become more frequent and intense [4], questions arise as to how the humanitarian system and its approaches can be adapted to make it more efficient in managing the increasing needs.

An interesting approach lies with the increasing use of geoinformation services combined with the efforts of digital volunteers. Both have already proven to substantially support relief activities of humanitarian organizations, such as the mapping activities after the earthquake in Nepal in 2015 
or during the Ebola epidemic in 2014/2015 [5,6]. During that time, these so-called digital volunteers started to map communities and roads in the most affected areas, who were coordinated through projects, such as Missing Maps [7] and the Humanitarian OpenStreetMap Team (HOT) [8]. These mapping efforts enable relief activities to focus on efficiently reaching out to the people in need. It is important to elucidate how projects and platforms, such as Missing Maps, can support the preparedness of communities and humanitarian organizations, such as the Red Cross and Red Crescent Societies (National Societies), before a disaster strikes.

The article describes the current experiences of the British Red Cross and German Red Cross, which are using Missing Maps within their international programmes. In the first section, this article describes the Missing Maps project and its structure, while the second section provides an overview of the Red Cross and Red Crescent Movement. The final section will then combine both areas by showing the current use and opportunities that Missing Maps offers for disaster risk reduction projects, hereby presenting different perspectives and current approaches.

\section{Missing Maps}

Missing Maps was launched in November 2014 by the American Red Cross, British Red Cross, HOT and Médecins Sans Frontières-UK with the goal "to map the most vulnerable places in the world". Other humanitarian organizations, research institutes and non-governmental organizations have since joined the collaboration. Their aims include addressing urgent humanitarian needs, to develop, learn from and grow the efficient use of the collected volunteered geographic information (VGI) as well as to involve volunteers within humanitarian programmes. While the previous efforts of digital volunteers mainly involved supporting the disaster response and relief during times of emergencies, the Missing Maps project focuses on existing humanitarian crises and programmes as well as disaster risk reduction. Since 2014, nearly 60,000 volunteers have contributed to Missing Maps mapping projects through the creation and validation of map material [7].

The crowdsourced mapping tasks of the Missing Maps project are based on deriving geographic information from remotely sensed imagery [9]. Remote global digital volunteers trace base map information, such as roads and buildings. The organization and digitization of this geographic information is conducted by a dedicated coordination tool, which is known as the HOT Tasking Manager [10]. On this platform, the mapping projects are split into small tasks, allowing the remote volunteers to work simultaneously on the same overall area (Figure 1a). The acquired VGI is made available for a wide range of applications by directly adding it to OpenStreetMap (OSM), which is a free and editable digital map of the world released with an open-content license [11].

Within humanitarian and disaster contexts, reliable data are crucial in enabling decision-making. As a result, questions related to the quality of OSM data often emerge. To ensure data quality, validation by experienced remote mappers and by local volunteers on the ground is integrated in the mapping workflow (Figure 1b). These local volunteers also contribute additional local detail, which could not be derived easily by remote volunteers from remotely sensed imagery. Reference datasets for extrinsic data quality assessment are rarely available for the areas of interest. However, the strong collaboration within Missing Maps between the academia and practice facilitates discussions on incorporating intrinsic quality evaluations by making use of the full historical OSM data [12].

Encouraging volunteers to spend time solving the mapping tasks is another crucial factor determining the success of the Missing Maps project. To fully utilise the volunteers' time and skills, Missing Maps provides different levels of engagement in the VGI activities. For example, mapping events, which are also called "Mapathons", are organised to bring newcomers and experienced contributors together in a social setting. The MapSwipe App [13], which was developed within the Missing Maps project, makes contributing convenient for individual volunteers, who classify remotely sensed imagery into "no building", "building" and "bad image" using their mobile phones [9]. In the next step, detailed geographic information is added through the detailed mapping of buildings in OSM. 
The collaboration within Missing Maps enables the exchange of ideas and challenges as well as joint work on relevant services and tools. Therefore, the Missing Maps approach not only enables data gathering, but also facilitates data quality assurance and innovation transfer. This has subsequently led to increasingly effective and informed OSM data use by organizations and local communities. In addition, the Missing Maps project aims to work in collaboration with the local community groups, using local expertise in a local context.

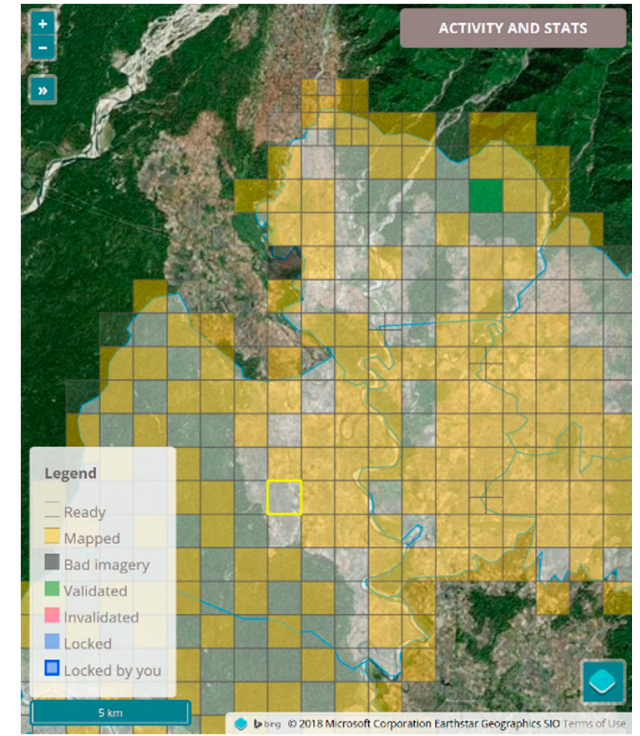

(a)

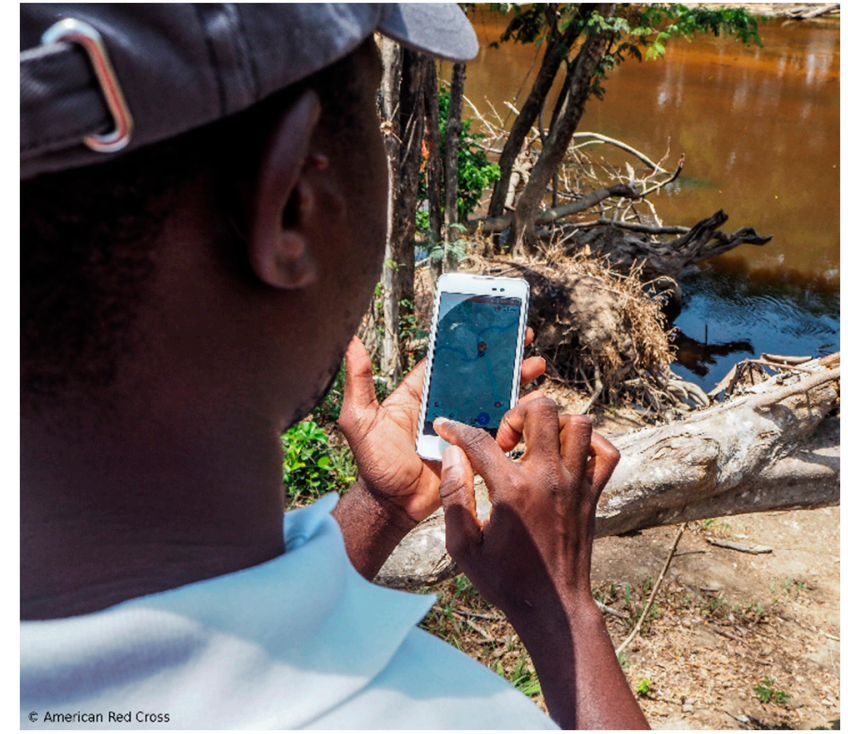

(b)

Figure 1. Missing Maps mapping projects are based on deriving volunteered geographic information from remotely sensed imagery. To ensure data quality, validation by local volunteers on the ground is integrated in the mapping workflow: (a) An example of a British Red Cross remote mapping project in the HOT Tasking Manager (https://tasks.hotosm.org/project/3677); and (b) A Red Cross and Red Crescent Movement volunteer uses an open source, freely accessible mobile application to verify a derived map.

\section{The Red Cross and Red Crescent Movement}

The British Red Cross (BRC) and the German Red Cross (GRC) are part of the worldwide Red Cross and Red Crescent Movement, which has components of the International Committee of the Red Cross (ICRC), the International Federation of Red Cross and Red Crescent Societies (IFRC) and 190 presently recognised National Societies. National Societies have the role of voluntary auxiliaries in the humanitarian services of their governments, including emergency aid in response to disasters. However, their assistance must always be delivered in compliance with the seven fundamental principles of the Red Cross and Red Crescent Movement.

As part of and in consultation with the other components of the Red Cross and Red Crescent Movement, the BRC and the GRC participate in humanitarian emergency and disaster responses, reconstruction and humanitarian oriented development cooperation worldwide. Such programmes and projects are always run in cooperation with the National Society in country. Their aims are to help those affected by disasters or conflicts according to their needs and to support the most vulnerable groups of the community in improving their living conditions. Furthermore, BRC and GRC promote civil society in partner countries by contributing to the structural development of the National Society in order to enable them to respond more effectively to the needs of their own community. 


\section{The Use of Missing Maps for the British and German Red Cross}

For the Red Cross and Red Crescent Movement, the Missing Maps project offers a number of opportunities. These opportunities include the response capacities of the respective National Society through improved maps before or after disasters strike; new ways of motivating volunteers to join the National Society; and new ways of informing the public about the importance of disaster risk reduction by letting them actively support projects through mapping. Finally, it also improves the decision-making about where to implement disaster risk reduction projects.

\subsection{Improving Disaster Risk Reduction and Response}

Within many developing countries, there is a lack of universally accessible maps that contain basic geographic information, such as roads, names of towns and villages or points of interest. This situation makes it difficult to prepare communities before a disaster strikes and to make informed decisions about where to focus relief activities after a disaster takes place. Existing and out-of-date maps can provide an indication of where affected communities might be but it is unclear if these cover every community and village in the affected region(s). Therefore, some communities, which are not represented on an online accessible map, such as OSM, might be less visible after being affected by a disaster. Adding geographic information to the map enables improved decision-making by the respective National Society and the potentially supporting Sister National Societies. It can also improve the responses of government authorities and other humanitarian NGOs as all information gained through Missing Maps are publicly available through the OSM database, which were obtained both pre- and post-disaster.

Putting villages and communities on the maps also supports the work of National Societies in terms of identifying areas at risk, such as locations where villages or vulnerable communities are situated along a river that is regularly flooded. Using this information, the National Society can begin to work together with these communities to prepare them for potential floods. Through participatory approaches, we can work together with the community members to identify ways to reduce the risks that they are facing and increase their capacities to deal with these risks.

Moreover, the Red Cross and Red Crescent Movement are increasingly working within the urban environment and informal settlements. A National Society can add points of interests and additional layers, such as buildings, which could support efforts to reinforce these houses to prepare them for earthquakes or floods. As urban environments and informal settlements can change rapidly, it is of utmost importance to ensure that these maps are updated on a regular basis in order to be able to analyse the situations in these settings. These updates must be both remotely sensed and validated on the ground.

\subsection{Strengthening the Volunteer Base}

As a volunteer-based organization, the Red Cross and Crescent Movement rely heavily on the global network of active and motivated volunteers. They are the ones supporting the implementation of projects in the communities and the first responders once a disaster takes place. Thus far, the Red Cross and Red Crescent Movement offer various training programs, such as first aid or search and rescue trainings, which is dependent on the respective National Society. As important as these trainings are, we need to be aware that these trainings are decreasing in their attractiveness to people, especially youth, and within urban areas. Thus, it is becoming increasingly important to offer trainings in which the use of digital tools, such as mobile phones, can be used to map communities or districts as this can be beneficial in strengthening the motivation of people to support the respective National Societies as volunteers, many of whom may already use digital tools.

The BRC, GRC and the Red Cross and Red Crescent Movement are looking to diversify their efforts to engage and motivate volunteers. Due to work and other commitments, volunteers often do not have a lot of time to spare. Therefore, the Missing Maps project can engage global volunteers 
on a more casual basis, allowing individuals to support the international work of BRC, GRC or other National Societies by mapping through the use of their mobile devices while sitting on the sofa for example. While mapping for the Red Cross and Red Crescent does not automatically make you an official volunteer, there is also still the need to identify ways on how to integrate potential mappers who would like to become official volunteers and do not have the time to physically visit their local branches.

Furthermore, the use of Missing Maps for the Red Cross Red Crescent Movement creates new ways to inform the public about the areas that we are working in. When people think about the Red Cross or the Red Crescent, they are likely to think about certain services, such as first aid, international and domestic disaster response, blood donations or services for the elderly. While these services are crucial, people are mostly not aware that the Red Cross and Red Crescent Movement are also active in the area of international humanitarian assistance and preparedness. As Missing Maps is very intuitive and is easily explained, it also enables the Red Cross Red Crescent Movement to explain humanitarian assistance and more specifically, what disaster risk reduction is about.

\subsection{Integrating Missing Maps into Standard Disaster Risk Reduction International Programming of the Red Cross and Red Crescent Movement}

With more than 100 million volunteers all around the world, the Red Cross and Red Crescent Movement could become a pioneer of creating open source data through projects, such as Missing Maps. Ideally, all programmes are supposed to start by conducting a so-called Vulnerability and Capacity Assessment (VCA), which involves identifying and assessing the existing natural hazards, the vulnerabilities and the response capacities of a community. A VCA takes into account local knowledge of natural hazards, the frequency of disasters and any pre-established structures, such as evacuation routes or safe refuges. Any functioning village committees are involved in the process. The tools of a VCA include hazard maps to identify the high-risk zones and safe places in each targeted community.

Thus far, only a few of the 190 National Societies are engaged in the Missing Maps project but an increasing number of National Societies are showing an interest in using the tools and processes surrounding it. If we can engage more National Societies to use Missing Maps and to validate the data through their local volunteers, the Red Cross and Red Crescent Movement could substantially improve the quality and quantity of data that are available in the OSM database and humanitarian data ecosystem. Within a VCA, Missing Maps could utilise remote volunteers to create VGI for the programme area. Using this information, local community groups can subsequently detail their risks on either paper or digitally using a geographic information system (GIS) or online tools. After this, any non-sensitive and open data can be added to the OSM database, with sensitive information held by the National Society.

The integration of digital mapping of the communities into the VCA has shown great promise. First attempts have already been conducted, with local volunteers finding that it was motivating to map their own communities and see the results of their mapping online within OSM [14]. However, the methodologies of VGI and online or digital tools for VCAs are still being created and tested. Case studies can only be collected by piloting VCAs using VGI and local volunteers using digital tools within a variety of geographic settings, such as urban, rural or informal settlements. National Societies can then utilise tools and methodologies that are most suitable for both their programmes and environments in which they work. Questions remain regarding how National Societies effectively use digital technology to include vulnerable groups and communities and how to ensure that these communities have access to the digital data produced.

If the Missing Maps approach was integrated into the programmes of the Red Cross and Red Crescent Movement standards, the benefits of the Missing Maps approach would not exclusive to the National Societies. By improving their response structures and by gaining new volunteers, the Red Cross and Red Crescent Movement can add major value across the whole humanitarian movement as 
a multitude of NGOs and governmental agencies can potentially use the maps to plan their projects or to plan relief activities in the aftermath of natural disasters.

The National Society in which the programme takes place will always be the main leader. Therefore, integration requires the National Society to first understand and identify the benefits of the use of the Missing Maps approach, before training volunteers and setting up the capacity within the National Society to process and analyse the collected data while ensuring sustainability.

\section{Conclusions and Future Potentials of Missing Maps}

Over the past few years, the Missing Maps approach has repeatedly proved its potential for humanitarian assistance and disaster management. While the project was launched by only four organizations, there are now 17 member organizations in Missing Maps, and nearly 60,000 mappers. The growing numbers of members, which include research institutes and the global volunteer mapping community, enables greater cross-learning regarding the current best practice (data gathering methods, data quality assurance, usage and usability) and the future potential of mapping community practices, processes and tools.

The Red Cross and Red Crescent Movement have recognised the potential of the Missing Maps project and its approach, acknowledging the crucial contributions of geographic information in driving disaster responses and recovery as well as preparedness. The global digital volunteers are becoming more involved and gaining a greater understanding of the Red Cross and Red Crescent Movement, while they are also becoming part of a humanitarian programme and connecting with the volunteer community in their country.

Vulnerability and Capacity Assessments (VCA) can utilise the Missing Maps approach and global volunteer network to enhance programmes. Currently, only a small number of VCAs are digital, with both VGI and local capacity information online. There is increasing scope for these assessments to become digital. However, the number of case studies remains limited and existing knowledge of tools, methodologies and initiatives within countries is limited throughout the humanitarian space although this is slowly increasing. With new tools and technology, National Societies should ensure that all activities undertaken are inclusive of communities, including community members that are not digitally enabled, and that access is not restricted.

Enabling National Societies and their volunteers to contribute to the OSM database, which is an open licensed and editable online map, could lead to global sharing of geographic information that is pertinent to vulnerable communities. Combined with collaboration between NGOs, local governmental agencies and community groups, these data, if continually updated, can become a resource for more efficient activities in the area of prevention, mitigation, preparedness, response and recovery for a disaster.

This article has solely focused on disaster risk reduction and the Missing Maps approach within the scope of VCAs. However, this approach of using remotely sensed information and VGI combined with ground level information is not only one-dimensional as the methodology can be used across a multitude of sectors within the humanitarian space, such as health, water and sanitation; shelter; and food security and livelihoods. The Missing Maps approach can assist in the digital inclusion of vulnerable communities, enabling them with tools and methodologies. These communities and individuals could later use this VGI combined with National Society and volunteer led data collection on the free editable OSM map to advocate for further action post-programme.

Author Contributions: Conceptualization, S.S., P.K., M.E., S.M. and A.Z.; Writing-Original Draft Preparation, S.S., P.K., M.E. and S.M; Writing-Review \& Editing, S.S., P.K., M.E., S.M. and A.Z.

Funding: This research was partly funded by the Klaus Tschira Stiftung, Heidelberg.

Conflicts of Interest: The authors declare no conflict of interest. The funders had no role in the design of the study; in the collection, analyses, or interpretation of data; in the writing of the manuscript, and in the decision to publish the results. 


\section{References}

1. Global Humanitarian Overview 2018. Available online: https://www.unocha.org/sites/unocha/files / GHO2018.PDF (accessed on 28 June 2018).

2. World Disasters Report 2016. Available online: http://media.ifrc.org/ifrc/publications/world-disastersreport-2016/ (accessed on 28 June 2018).

3. Global Facility for Disaster Reduction and Recovery. Global Facility for Disaster Reduction and Recovery. 2014. Understanding Risk in an Evolving World: Emerging Best Practices in Natural Disaster Risk Assessment; The World Bank: Washington, DC, USA, 2014; Available online: https:/ / www.gfdrr.org/sites/gfdrr/files/publication/ Understanding_Risk-Web_Version-rev_1.8.0.pdf (accessed on 30 July 2018).

4. IPCC. Summary for policymakers. In Climate Change 2014: Impacts, Adaptation, and Vulnerability. Part A: Global and Sectoral Aspects. Contribution of Working Group II to the Fifth Assessment Report of the Intergovernmental Panel on Climate Change; Cambridge University Press: Cambridge, UK; New York, NY, USA, 2014; pp. 1-32.

5. Poiani, T.H.; dos Santos Rocha, R.; Degrossi, L.C.; de Albuquerque, J.P. Potential of Collaborative Mapping for Disaster Relief: A Case Study of OpenStreetMap in the Nepal Earthquake 2015. In Proceedings of the 49th Hawaii International Conference on System Sciences (HICSS '16), Koloa, HI, USA, 5-8 January 2016; IEEE Computer Society: Washington, DC, USA, 2016; pp. 188-197.

6. Nic Lochlainn, L.M.; Gayton, I.; Theocharopoulos, G.; Edwards, R.; Danis, K.; Kremer, R.; Kleijer, K.; Tejan, S.M.; Sankoh, M.; Jimissa, A.; et al. Improving mapping for Ebola response through mobilising a local community with self-owned smartphones: Tonkolili District, Sierra Leone, January 2015. PLoS ONE 2018, 13. [CrossRef] [PubMed]

7. Missing Maps. Available online: http://www.missingmaps.org/ (accessed on 28 June 2018).

8. Humanitarian OpenStreetMap Team. Available online: https:/ / www.hotosm.org/ (accessed on 28 June 2018).

9. Albuquerque, J.; Herfort, B.; Eckle, M. The Tasks of the Crowd: A Typology of Tasks in Geographic Information Crowdsourcing and a Case Study in Humanitarian Mapping. Remote Sens. 2016, 8, 859. [CrossRef]

10. HOT Tasking Manager. Available online: https://tasks.hotosm.org/ (accessed on 28 June 2018).

11. OpenStreetMap Wiki. Available online: https://wiki.openstreetmap.org (accessed on 28 June 2018).

12. Auer, M.; Eckle, M.; Fendrich, S.; Griesbaum, L.; Kowatsch, F.; Marx, S.; Raifer, M.; Schott, M.; Troilo, R.; Zipf, A. Towards Using the Potential of OpenStreetMap History for Disaster Activation Monitoring. In Proceedings of the 15th ISCRAM Conference, Rochester, NY, USA, 20-23 May 2018.

13. MapSwipe. Available online: http:/ / mapswipe.org/ (accessed on 28 June 2018).

14. Liu, W.; Dugar, S.; McCallum, I.; Thapa, G.; See, L.; Khadka, P.; Budhathoki, N.; Brown, S.; Mechler, R.; Fritz, S.; et al. Integrated Participatory and Collaborative Risk Mapping for Enhancing Disaster Resilience. IJGI 2018, 7, 68. [CrossRef]

(C) 2018 by the authors. Licensee MDPI, Basel, Switzerland. This article is an open access article distributed under the terms and conditions of the Creative Commons Attribution (CC BY) license (http:/ / creativecommons.org/licenses/by/4.0/). 